\title{
1. Introduction to the Handbook of Digital Inequality
}

\author{
Eszter Hargittai
}

For a term that barely existed two decades ago, digital inequality has certainly made its mark on academic scholarship. In its relatively short life as an academic domain of inquiry, digital inequality has amassed an immense amount of scholarly attention. According to Google Scholar, over ten thousand papers refer specifically to "digital inequality" and tens of thousands of others to variations of the "digital divide." It is not only beyond the scope of any one piece to address every aspect of such a significant body of research, it is beyond the scope of any volume to do so as well. Instead, this Handbook presents important fresh insights about significant aspects of digital inequality that are of enduring value.

Digital inequality refers to how people of different backgrounds incorporate the Internet into their lives; how their digital and social contexts, their skills and their uses differ (DiMaggio \& Hargittai, 2001), and how the life outcomes associated with these differences vary (Hargittai, 2008). The more common term "digital divide" refers to differences between those who are connected and those who are not, in other words, basic access differences between the information rich and poor (Hoffman \& Novak, 1998). While such a divide continues to exist in most parts of the world and deserves continued attention, it is not the topic of this book. The focus of digital inequality scholarship is identifying differences among users.

Already in the early 2000s, scholars started being critical of the simplistic "digital divide" term, arguing that it did not capture the various levels at which people's uses of information and communication technologies may differ (Attewell, 2001; Fink \& Kenny, 2003; Hargittai, 2002; Katz \& Rice, 2002; Mossberger et al., 2003; Natriello, 2001; Selwyn, 2002; van Dijk, 2000; Warschauer, 2002). While Attewell (2001) seems to have been the first to refer to the "second digital divide" pointing out differences in uses in addition to access (p.253), it looks like I may have been the first to publish using the phrase "second-level digital divide" (Hargittai, 2002).

Concurrently, my graduate advisor Paul DiMaggio and I co-authored a working paper published by the Princeton University Center for Arts and Cultural Policy Studies titled "From the 'digital divide' to 'digital inequality': studying Internet use as penetration increases" (DiMaggio \& Hargittai, 2001), which seemed to be the first instance of suggesting the phrase "digital inequality" in the context of the "digital divide" literature. ${ }^{1}$ Why I opted for using "second-level digital divide" instead of "digital inequality" in my First Monday piece about skill differences (Hargittai, 2002) is not clear to me two decades later. One reason may have been to be in conversation with the "digital divide" literature directly. The main point was to suggest that inequalities would persist beyond access differences, which is the goal of this Handbook and thus the use of the "digital inequality" phrase in its title and throughout many of the chapters.

Continued advancement in the field of digital inequality is needed to keep up with trends in an ever-changing digital media lanscape. As new technologies diffuse and older ones evolve, 


\section{Handbook of digital inequality}

their adoption rates across the population will change. People's skills in using different services are also likely to progress over time, including the development of new skills in an evolving media environment. Such transformation requires not only ongoing data collection, but also the continuous development of new theories, methods, and measures. This makes for an exciting area of research with ongoing challenges, but also opportunities.

Sustained progress is also imperative, because work in many other domains that study digital media makes incorrect assumptions about who uses which technologies (whether that be devices or services) in what ways to what ends and with what consequences. It is up to digital inequality research to keep other domains of inquiry in check about their assumptions and to inform them about variations in adoption rates and skills. Studies that use specific platforms as their sampling base, for example, by definition ignore people who are not users of said platforms. Given that adoption of those platforms is usually not randomly distributed (Blank \& Lutz, 2017; Gazit et al., 2019; Hargittai, 2007, 2015, 2020; Hargittai \& Litt, 2011; Hellemans et al., 2020; Mellon \& Prosser, 2017; Tufekci, 2014) means systematic biases against certain groups of people, whose opinions and behaviors researchers are analyzing.

As digital media infiltrate every domain of life and thus academic scholarship, digital inequality research must persist with rigorous theorizing and empirical work. This collection serves as a blueprint for the kind of investigation that should be of interest not just to those with a primary focus on questions of social stratification, but to all those curious about the social, political, cultural and economic implications of digital media writ large. Varied adoption, skills and patterns of use may have consequences for all of those domains. And, importantly, such investigation is also significant for informing policy, whether at the local, national, or international level, to encourage equitable digital opportunities.

\section{IN THIS HANDBOOK}

The chapters in this volume move digital inequality research forward through the investigation of areas heretofor not covered in sufficient detail in the literature. The rich collection of mostly empirical pieces representing multiple countries around the globe gives insights into what contemporary digital inequality looks like and also inspires avenues for future work. The chapters are organized into four parts, although some chapters could easily fit into more than one section. These are: infrastructures and geographies, digital inequality throughout the lifecourse, health and disability, and privacy and trust.

Part I focuses on infrastructures and geographies reminiscent of initial digital divide studies about access, but raising this concept to the level of digital inequality research by investigating differences in access quality. Amy Gonzales has done much work on the concept of technology maintenance, that is, the important observation that some segments of the population struggle with continued reliable access to the Internet despite wanting and needing to be online (Gonzales, 2016). This idea harkens back to the importance of autonomy of use as an important dimension of digital inequality by noting the significance of having access when and where one wants (DiMaggio \& Hargittai, 2001; Hassani, 2006). With their innovative approach of content analyzing surveys about digital inequality, Gonzales and her colleagues (Chapter 2) make the case that most existing data-collection efforts ignore technology maintenance and they do so at their peril. 
Next, Forman and colleagues (Chapter 3) review the literature on geographic inequality and the Internet by examining how the Internet's regional diffusion relates to economic activity in the United States. Although economists have not been frequent contributors to digital inequality scholarship, they show how this domain is significant to that field, and also how digital inequality research can benefit from such a perspective on outcomes related to differentiated access at the regional level. Importantly, they find that offline differences translate into variations in how the Internet impacts a region.

Schrubbe and Strover (Chapter 4) focus on one specific type of region: rural communities in the USA. They explain why rural communities have consistently lagged behind urban areas in various types of Internet access and offer lessons learned from successful cases of providing broadband to rural communities as a way to improve connectivity quality more broadly. While partly focusing on access-level questions, the contribution to digital inequality scholarship is in the emphasis on the importance of quality access. Quality of connectivity beyond mere access has been an important dimension of digital inequality scholarship from the beginning (DiMaggio \& Hargittai, 2001) although nowadays is too often taken for granted as a given in all areas.

Continuing the theme of rural access options, Correa and colleagues (Chapter 5) look at how a large policy initiative in Chile - one of the most connected countries in Latin America - managed to get online remote areas in that country through mobile access. But they also find that mobile and other access are qualitatively different both in relation to Internet skills and usage so focusing on just one does not address all digital inequality concerns. Rounding out Part I, Helsper (Chapter 6) makes the case that the places where people live and their social networks are an important part of understanding how people incorporate the Internet into their lives. She draws on data collected through mixed methods in several Los Angeles and London neighborhoods for her analyses. The social aspects of use and neighborhood effects are indeed oft-neglected dimensions of digital inequality even though early research had already noted the central importance of social context to understanding people's varied skills and usage (Hargittai, 2003).

Part II looks at inequality through the lifecourse with several chapters focusing on youth and young adults, one on working-age adults, and the rest on older adults. Perhaps not surprisingly, given the increasing importance of mobile media, several chapters about teens and young adults are preoccupied with understanding the role of mobile phones in these users' lives. Chapter 7 by kimm and Boase relies on interviews with high school students in Canada to examine how teens leverage such devices for information seeking and relationship maintenance. One important finding is that teens' skills are not universal despite having grown up with technologies. Rather, skills depend on the quality of their access. Next, Kim and Hargittai (Chapter 8) look back at a time when mobile media was first taking off among young adults in the USA to see how their uses varied by socio-demographics and Internet experiences. Like the previous chapter, they also find variations in skills and note that these explain differentiated usage.

Countering assumptions that more use is necessarily better, the next two chapters look at the potential downsides of higher levels of technology engagement. Gui and Gerosa (Chapter 9) focus on how mobile use may influence the important outcome of school performance. They analyze survey data from Italy and find that more frequent smartphone use of youth from families of lower socioeconomic status is linked to lower school performance. Micheli (Chapter 10) reports on interviews she conducted with low-income youth and young adults in 
Italy to understand their approach to Facebook. She finds that such users actively resist the platform and discusses what implications this has for digital inequality scholarship. Chapter 11 by Brown and Ellison is interested in a specific use of social media: to learn about college. Their focus is on how American young adults from low-income backgrounds can use social media to get support with their transition to college. They find that while the potential is there, the social norms associated with what content people share on such services limits the utility of such information flows and support.

Analyzing national survey data about Polish working-age adults, Drabowicz (Chapter 12) looks at what factors explain differences in people's digital skills. He finds that traditional markers of inequality such as lower education, lower income, and being in a less skilled occupation all relate to lower skills. Contributing a new dimension to related scholarship, he also shows that those employed in the public sector also exhibit lower skills. The remaining two chapters in this section focus on older adults. The first by Quan-Haase and colleagues (Chapter 13) draws on interviews conducted in Canada to challenge assumptions about older adults as a uniform group of disengaged digital media users. Rather, they find considerable variation in uses and skills including some very savvy older adults with an eagerness to improve their digital literacy. They also note that active usage and high skills are not always linked challenging a prevalent approach to measuring skills by simply measuring use (OECD, 2019). Kadylak and Cotten (Chapter 14) rely on national survey data of US adults 65+ to consider how online social connectedness relates to various well-being indicators. They find that older adults who see benefits to using the Internet for social connection have higher well-being indicators in the realm of mattering, social support, and life satisfaction.

Part III is an extension of that last chapter by focusing entirely on the domains of health and disability. Bonfadelli (Chapter 15) starts this section by offering a review of the literature on health and digital inequality, first conceptually, and then through empirical cases across national contexts. Li and Chen (Chapter 16) report on the health-related technology uses of low-income public-housing residents based on survey data they collected in the Southern USA. They differentiate basic digital skills and eHealth literacy finding that the two play different roles in people's online health information searching and mobile health management.

The other two chapters in this section are concerned with digital inequality and disabled people. Goggin (Chapter 17) reviews existing literature in this domain including related policy and then goes on to point out major challenges that this area of scholarship faces such as agreement on the definition of disability and lack of adequate data sets to dig deep into the digital experiences of disabled people. Dobransky and Hargittai (Chapter 18) then offer an empirical piece by looking at two data sets collected just over a decade apart. They look at whether disabled people have made gains in their Internet skills in comparison to others over time and find this to be the case.

Part IV turns to the topic of privacy and trust. While an enormous amount of scholarship exists on these topics, they have thus been less present in work on digital inequality. As the chapters in this section show, however, this domain is ripe for such investigations. As one of the pioneers of such research, Park (Chapter 19) is well-positioned to offer a helpful review of related literature and a theoretical framework for how to approach future work on privacy and digital inequality. Büchi and colleagues (Chapter 20) empirically test how socio-demographics, Internet uses, skills, privacy attitudes, and experiences with privacy breaches relate to privacy-protective behaviors. Their analyses of national survey data about Swiss adults' online 
experiences show a clear digital inequality story with Internet skills playing an important role in the puzzle.

In Chapter 21, Redmiles and Buntain look at how trust in institutional actors, concern about online scams, and control of personal data relate to what people do online. Analyzing national survey data of US adults, they find that while traditional markers of inequality explain variations in online behaviors, including measures of the above-listed factors significantly improves model fit and thus encourages more focus on such variables in future work. Lutz and Hoffmann (Chapter 22) turn to the specific activity of political participation to consider the role privacy concerns may play in its variation. They analyze survey data of German Internet users and find that privacy concerns exhibit a positive relationship with such online behavior although its inclusion only improves model fit slightly when accounting for social media use.

In their chapter on exploring algorithm skills and search engine use, Reisdorf and Blank (Chapter 23) analyze national survey data of American adults. They find that algorithmic literacy is related to traditional markers of inequality. They also note that algorithm skills are a construct distinct from search skills suggesting more work for this important new domain of skills (Hargittai et al., 2020). Walker and Hargittai (Chapter 24) round out this section with a qualitative piece based on focus group interviews with young adults in the USA to explore where such users learn their skills in the first place. They find that a mix of personal and social experiences in addition to institutional nudges and third-party content such as media coverage inform what people know about how the Internet works. This points to potential avenues for interventions on improving people's digital skills.

\section{PERSISTING DIGITAL INEQUALITIES REQUIRE ONGOING SCHOLARLY INVESTIGATION AND POLICY INTERVENTIONS}

As evidenced by the plentiful material in this Handbook, digital inequality scholarship has come a long way in identifying the many important ways in which people of different backgrounds access and use technologies differently, in how their skills vary, and how all these divergences impact differential life outcomes. The work is not done, however. As technologies evolve, so do the skills necessary to use them effectively, efficiently, and in an informed way. Thus even if people catch up with some abilities over time, new developments emerge that are likely to result in new skill differences. As the chapters in this Handbook show, lots of variations continue to persist in how people incorporate digital media into their lives. Variation in and of itself is not necessarily a cause for concern, but it is when people from less privileged backgrounds have fewer opportunities to benefit from digital media, and are more prone to problematic outcomes or being left behind. As the Handbook collection shows, that tends to be the case.

The field gains from welcoming a multitude of methods as evidenced by the diverse set of approaches represented in the chapters of this volume. They can be applied to all dimensions of digital inequality from the digital and social contexts of use to skills, to informational as well as participatory uses, and to life outcomes in domains as varied as health and well-being, academic achievement, job prospects, social connectedness, political participation, creative output, and the list goes on. While costly, there is a growing need for longitudinal studies of the same respondents, i.e., panel studies, as well as cross-country comparisons. It also behooves the community to keep the policy implications of this work at the forefront and take 


\section{Handbook of digital inequality}

steps to communicate the findings to relevant constituents and the public at large. There is no shortage of research questions. Many contributions in this volume are by junior scholars, which suggests that the future is bright for this important domain of inquiry.

\section{NOTE}

1. Although Timothy W. Luke (1997) did use the phrase "digital inequality" in a book chapter in 1997, he did not directly link this to discussion of the "digital divide." I was not aware of that piece at the time of our writing.

\section{REFERENCES}

Attewell, P. (2001). The first and second digital divides. Sociology of Education, 74(3), 252-9.

Blank, G., \& Lutz, C. (2017). Representativeness of social media in Great Britain: investigating Facebook, LinkedIn, Twitter, Pinterest, Google+, and Instagram. American Behavioral Scientist, 61(7), 741-56. https://doi.org/10.1177/0002764217717559.

DiMaggio, P., \& Hargittai, E. (2001). From the "Digital Divide" to "Digital Inequality": Studying Internet Use as Penetration Increases (No. 47; Working Papers). Princeton University, Woodrow Wilson School of Public and International Affairs, Center for Arts and Cultural Policy Studies. https:// culturalpolicy.princeton.edu/sites/culturalpolicy/files/wp15_dimaggio_hargittai.pdf.

Fink, C., \& Kenny, C. J. (2003). W(h)ither the digital divide? Info, 5(6), 15-24. https://doi.org/10.1108/ 14636690310507180.

Gazit, T., Aharony, N., \& Amichai-Hamburger, Y. (2019). Tell me who you are and I will tell you which SNS you use: SNSs participation. Online Information Review, 44(1), 139-61. https://doi.org/10.1108/ OIR-03-2019-0076.

Gonzales, A. (2016). The contemporary US digital divide: from initial access to technology maintenance. Information, Communication \& Society, 19(2), 234-48. https://doi.org/10.1080/1369118X.2015 .1050438 .

Hargittai, E. (2002). Second-level digital divide: differences in people's online skills. First Monday, 7(4). http://firstmonday.org/ojs/index.php/fm/article/view/942.

Hargittai, E. (2003). Informed web surfing: the social context of user sophistication. In P. Howard \& S. Jones (eds.), Society Online I (pp.257-74). Thousand Oaks, CA: Sage Publications.

Hargittai, E. (2007). Whose space? Differences among users and non-users of social network sites. Journal of Computer-Mediated Communication, 13(1), 276-97. https://doi.org/10.1111/j.1083-6101 .2007.00396.x.

Hargittai, E. (2008). The digital reproduction of inequality. In D. Grusky (ed.), Social Stratification (pp.936-44). Westview Press.

Hargittai, E. (2015). Is bigger always better? Potential biases of Big Data derived from social network sites. The ANNALS of the American Academy of Political and Social Science, 659(1), 63-76. https:// doi.org/10.1177/0002716215570866.

Hargittai, E. (2020). Potential biases in Big Data: omitted voices on social media. Social Science Computer Review, 38(1), 10-24. https://doi.org/10.1177/0894439318788322.

Hargittai, E., Gruber, J., Djukaric, T., Fuchs, J., \& Brombach, L. (2020). Black box measures? How to study people's algorithm skills. Information, Communication \& Society, O(0), 764-75. https://doi.org/ 10.1080/1369118X.2020.1713846.

Hargittai, E., \& Litt, E. (2011). The tweet smell of celebrity success: explaining variation in Twitter adoption among a diverse group of young adults. New Media \& Society, 13(5), 824-42. https://doi .org/10.1177/1461444811405805.

Hassani, S. N. (2006). Locating digital divides at home, work, and everywhere else. Poetics, 34(4-5), 250-72. https://doi.org/10.1016/j.poetic.2006.05.007. 
Hellemans, J., Willems, K., \& Brengman, M. (2020). Daily active users of social network sites: Facebook, Twitter, and Instagram-use compared to general social network site use. In F. J. Martínez-López \& S. D'Alessandro (eds.), Advances in Digital Marketing and eCommerce (pp.194-202). Springer International Publishing. https://doi.org/10.1007/978-3-030-47595-6_24.

Hoffman, D. L., \& Novak, T. P. (1998). Bridging the racial divide on the Internet. Science, 280(5362), 390-91.

Katz, J. E., \& Rice, R. E. (2002). Social Consequences of Internet Use: Access, Involvement and Interaction. MIT Press. https://mitpress.mit.edu/books/social-consequences-Internet-use.

Luke, T. W. (1997). The politics of digital inequality: access, capability and distribution in cyberspace. In C. Toulouse \& T. W. Luke (eds.), The Politics of Cyberspace (pp.120-43). Routledge.

Mellon, J., \& Prosser, C. (2017). Twitter and Facebook are not representative of the general population: political attitudes and demographics of British social media users. Research \& Politics. https://doi .org/10.1177/2053168017720008.

Mossberger, K., Tolbert, C. J., \& Stansbury, M. (2003). Virtual Inequality: Beyond the Digital Divide. Georgetown University Press.

Natriello, G. (2001). Bridging the Second Digital Divide: what can sociologists of education contribute? Sociology of Education, 74(3), 260-65.

OECD. (2019). Use of skills in everyday life and at work. In Skills Matter, Additional Results from the Survey of Adult Skills. OECD Publishing. https://doi.org/10.1787/1 f029d8f-en.

Selwyn, N. (2002). Defining the "digital divide": developing a theoretical understanding of inequalities in the information age. School of Social Sciences, Cardiff University. http://ictlogy.net/bibliography/ reports/projects.php?idp $=348$.

Tufekci, Z. (2014). Big questions for social media big data: representativeness, validity and other methodological pitfalls. In, ICSWSM '14 (pp.505-14). https://arxiv.org/abs/1403.7400.

van Dijk, J. A. G. M. (2000). Widening information gaps and policies of prevention. In K. L. Hacker \& J. A. G. M. van Dijk (eds.), Digital Democracy (pp.166-83). SAGE Publications.

Warschauer, M. (2002). Reconceptualizing the digital divide. First Monday, 7(7). http://dx.doi.org/10 $.5210 / \mathrm{fm} . v 7 \mathrm{i} 7.967$. 